MATEC Web of Conferences 22,04023 (2015)

DOI: $10.1051 /$ matec conf/ 20152204023

(C) Owned by the authors, published by EDP Sciences, 2015

\title{
Static Test and Result Analysis on Different Types of Pile Composite Foundation in the Same Field
}

\author{
Tuo Zhao* \\ Hebei Jianyan Technology Co., LTD, Shijiazhuang, Hebei, China \\ Weiyu Wang \\ Hebei Aademy of Buliding Research, Shijiazhuang, Hebei, China \\ Panxing Zhang \\ Hebei Mechanical and Electrical Professional Technology Institute, Xingtai, Hebei, China
}

\begin{abstract}
Combining with the situation of soil test site, the large scale experiment was studying about natural foundation, rammed soil-cement piles, CFG pile and gravel pil. A series of conclusions were given from $\mathrm{p}-\mathrm{s}$ curve, the fitting curve, and the Angle of the stress ratio of pile-soil composite modulus. It has certain guiding significance for the design and construction of pile type, which is used in North China area
\end{abstract}

Keywords: Compaction soil-cement pile; CFG pile ;Gravel pile ;Pile soil stress ratio ;Composite modulus

\section{RESEARCH SITUATION AND PURPOSE}

CFG pile is a representative of the rigid pile, which is made of cement, fly ash, gravel, sand stone chips and belongs to high bond strength pile. It is together with soil between the pile and mattress layer to form a composite foundation, and it was used for the tall buildings. Rammed soil-cement pile is a representative of the semi-rigid pile, which is medium bond strength pile. The uniform of cement-soil pile was made by using manual or mechanical pore forming, choosing relatively single soil materials, and mixing in a certain proportion to cement to hold backfill layer and strong ramming. Gravel pile is a representative of the flexible pile, which is a gravel (pebbles) or coarse sand as the main materials such as composite pile foundation reinforcement

At present, it has been relatively mature on view of the single pile composite foundation theory and the study of the static problem ${ }^{[1-6]}$, many studies about different pile types in the same site with finite element numerical simulation. It was few about large scale experiment. In order to further study the static characteristics of different types of pile composite foundation, combining with the situation of soil test site, the large scale experimental were studied about natural foundation, rammed soil-cement piles, CFG pile and gravel pil. A series of conclusions were given from p-s curve, the fitting curve, and the Angle of the stress ratio of pile-soil composite modulus. It has certain guiding significance for the design and construction of pile type, which is used in North China area.

\section{COMPOSITE FOUNDATION BEARING CA- PACITY CALCULATION}

According to certain principle of superposition, single pile composite foundation bearing capacity includes

*Corresponding author: zt940128@126.com pile bearing capacity and bearing capacity of soil between piles.

The formula is as follows:

$$
f_{s p k}=m f_{p k}+\beta(1-m) f_{s k}
$$

$f_{\text {spk }}$ : Characteristic value of bearing capacity of composite foundation $(\mathrm{kPa})$;

$\mathrm{m}$ : Rate of replacement;

$f_{p k}$ : Characteristic value of bearing capacity of pile $(\mathrm{kPa})$

$f_{s k}$ : After processing of soil between piles bearing capacity characteristic value $(\mathrm{kPa})$;

$\beta$ : The bearing capacity between soil coefficient. Gravel pile composite foundation: $\beta=1.0$; Rammed soil-cement piles composite foundation: $\beta=0.9-1.0$; CFG pile composite foundation: $\beta=0.75-0.95$.

\section{TEST}

\subsection{Geology}

According to the geotechnical engineering investigation report, within the scope of the $20 \mathrm{~m}$ depth reveal formation in addition to the surface of artificial soil, there existed the quaternary alluvial facies sedimentary formation. The soil total of five layers is planting soil, silty clay and fine sand and medium sand from up to down. The test did not involve the groundwater. And regardless of the liquefaction. the site formation distribution and mechanical parameters are shown in Table 1. 


\section{MATEC Web of Conferences}

Table 1. The site formation distribution and mechanical parameters

\begin{tabular}{|c|c|c|c|c|c|c|}
\hline The soil & $\begin{array}{l}\text { The } \\
\text { thickness }\end{array}$ & $\begin{array}{l}\text { The characteris- } \\
\text { tic value of } \\
\text { bearing capacity } \\
\text { fak } / \mathrm{kPa}\end{array}$ & $\begin{array}{l}\text { The com- } \\
\text { pression mod- } \\
\text { ulus Es/MPa }\end{array}$ & $\begin{array}{l}\text { Extreme } \\
\text { lateral } \\
\text { resistance } \\
/ \mathrm{kPa}\end{array}$ & $\begin{array}{l}\text { Ultimate end } \\
\text { resistance } \\
\text { standard } / \mathrm{kPa}\end{array}$ & The characteristics \\
\hline $\begin{array}{l}\text { Miscellaneous } \\
\text { fill }\end{array}$ & $0.2 \mathrm{~m}$ & - & - & - & - & $\begin{array}{l}\text { Brown, slightly thick, } \\
\text { toughness is low; The } \\
\text { surface of the original } \\
\text { planting soil; }\end{array}$ \\
\hline Silty clay & $0.5 \mathrm{~m}$ & 130 & 6.17 & 60 & - & $\begin{array}{l}\text { Tan, plastic } \sim \text { RuanSu, } \\
\text { tenacity is medium, } \\
\text { clamp silt thin layer, } \\
\text { mix powder soil mass; }\end{array}$ \\
\hline Fine sand & $1.5 \mathrm{~m}$ & 140 & 10 & 55 & 800 & $\begin{array}{l}\text { Gray, Micronesia, } \\
\text { quartz feldspathic, } \\
\text { sorting, sandy is pure; }\end{array}$ \\
\hline Medium sand & $8 \mathrm{~m}$ & 200 & 11.5 & 82 & 1500 & $\begin{array}{l}\text { Gray, Micronesia, } \\
\text { sandy pure, sorting, } \\
\text { quartz stone long }\end{array}$ \\
\hline Silty clay & $10 \mathrm{~m}$ & 270 & 5.84 & 65 & 1000 & $\begin{array}{l}\text { Tan, plastic } \sim \text { hard } \\
\text { plastic, toughness of } \\
\text { medium, including } \\
\text { loess-doll and iron } \\
\text { manganese rendering. }\end{array}$ \\
\hline
\end{tabular}

\begin{tabular}{|c|c|c|c|c|c|}
\hline $\begin{array}{l}\text { Type of composite founda- } \\
\text { tion }\end{array}$ & symbol & $\begin{array}{l}\text { The length } \\
/ \mathrm{m}\end{array}$ & $\begin{array}{l}\text { The diameter } \\
/ \mathrm{mm}\end{array}$ & $\begin{array}{l}\text { The pile spacing } \\
/ \mathrm{mm}\end{array}$ & $\begin{array}{l}\text { Rate of replace- } \\
\text { ment }\end{array}$ \\
\hline Rammed soil-cement pile & CSP & 6.0 & 350 & 1000 & 0.096 \\
\hline CFG pile & CFGP & 6.0 & 350 & 1000 & 0.096 \\
\hline Gravel pile & GP & 6.0 & 350 & 1000 & 0.096 \\
\hline
\end{tabular}

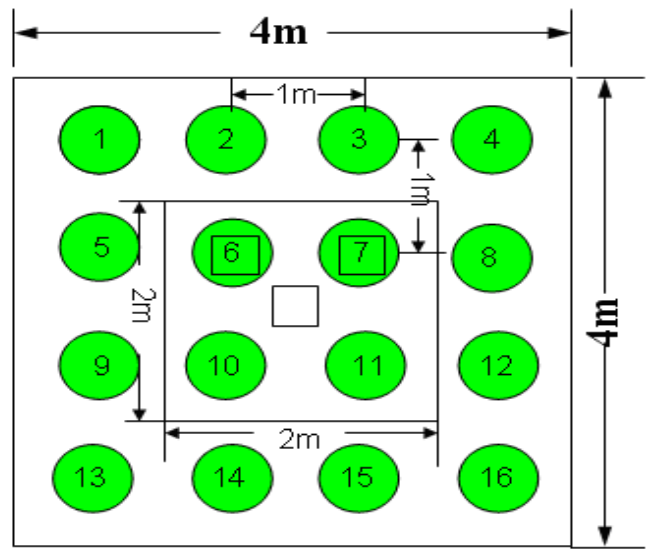

Figure 1. CSP layout

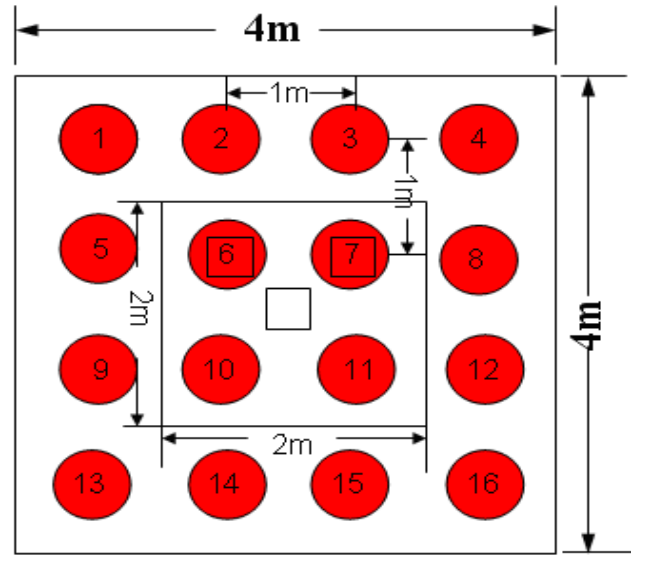

Figure 2. CFG layout 


\subsection{Test model}

The experiment selects three typical rammed soil-cement piles, pile type (CSP) and CFG pile (CFGP) and gravel pile composite foundation (GP). The design parameters of composite foundation of the model were shown in Table 2. CFGP adopted C20 concrete. The proportion of cement and soil in CSP was 1:7, and the particle size of gravel for GP was 20 $\sim 50 \mathrm{~mm}$.

CSP, CFGP and GP composite foundation layout was shown in Figures 1 to 3 . Test pile numbers were 6 \#, 7 \#, 10 \#, and 11 \#. The pressure box at the top of the test pile was used to measure the top of the pile stress. The pressure box on the surface of soil between piles was used to measure the top of the soil stress.

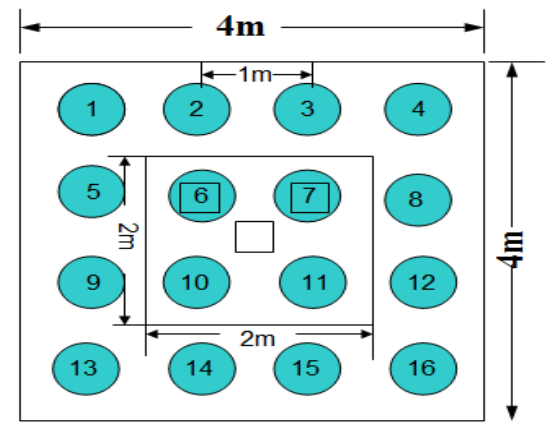

Figure 3. GP layout

\section{TEST RESULTS ANALYSIS}

\section{1 composite foundation curve of $p-s$}

The field experiment used three different composite foundations, and each set of test all used the same load level. The step was $45 \mathrm{kpa}$. The size of loading plate was $2 * 2 \mathrm{~m}$, and the thickness was $20 \mathrm{~mm}$. In order to prevent the load board corners tilted, increased steel beam on the load board. The levers were $45 \mathrm{kpa}, 90$ kpa, $135 \mathrm{kpa}, 180 \mathrm{kpa}, 225 \mathrm{kpa}$ and $270 \mathrm{kpa}$.

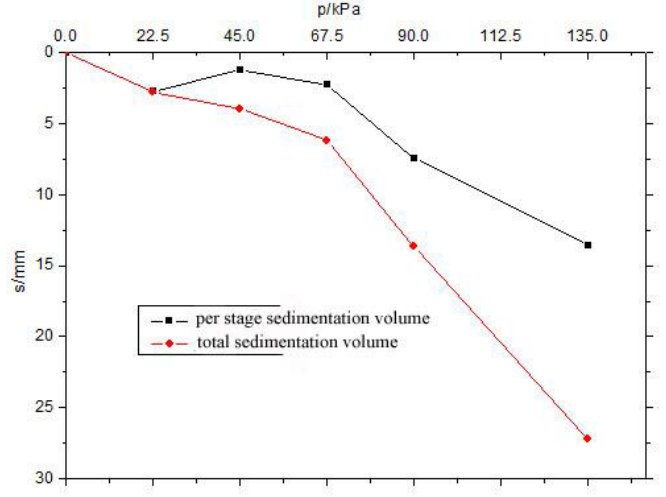

Figure 4. Natural foundation $\mathrm{p}-\mathrm{s}$ curve

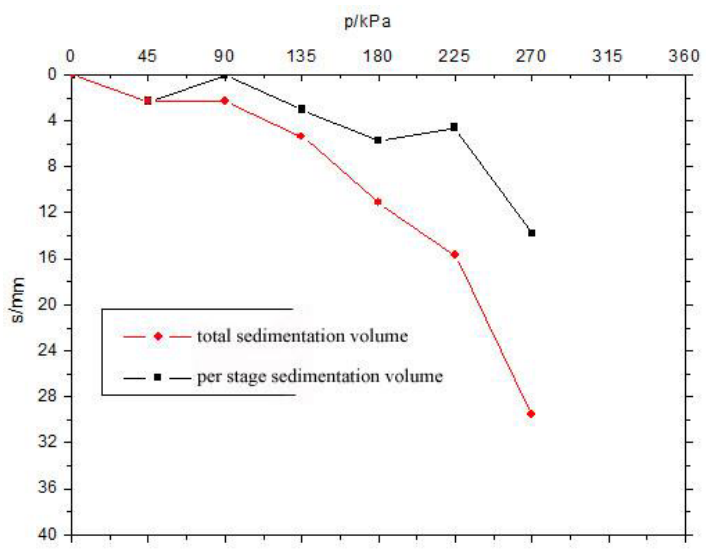

Figure 5. CSP $\mathrm{p}$ - $\mathrm{s}$ curve

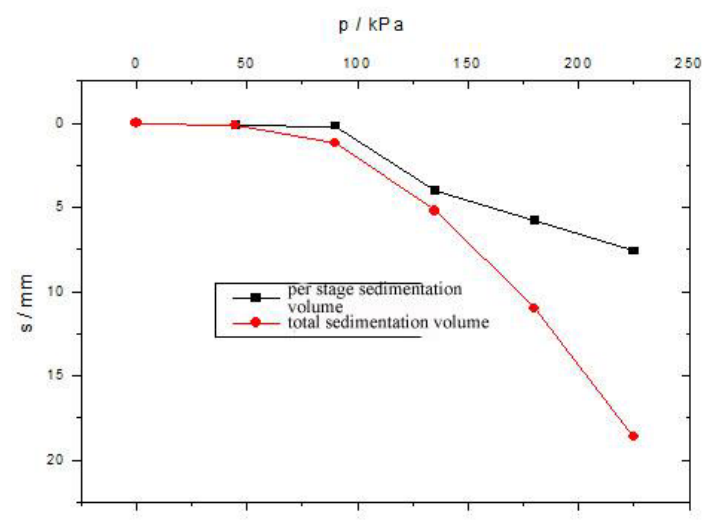

Figure 6. CFG p - s curve

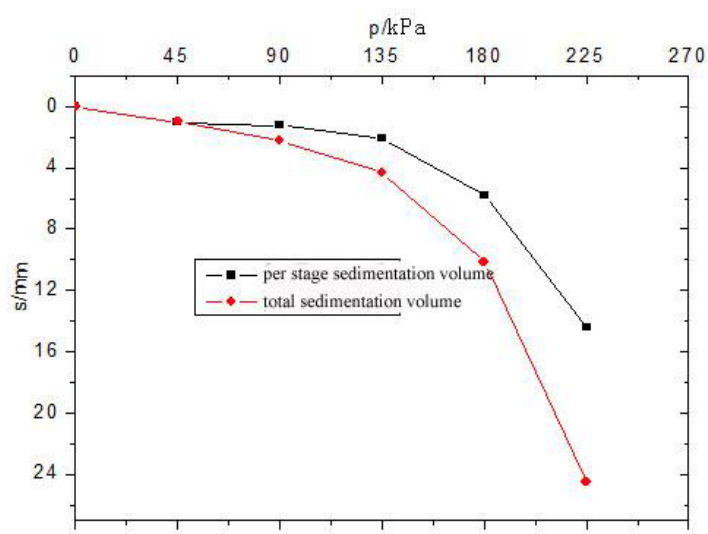

Figure 7. GP $\mathrm{p}$ - s curve

The p-s curve of natural foundation, rammed soil-cement piles, CFG pile and gravel pile composite foundation were shown on Figures 4-7. The figures showed that after treatment bearing capacity of composite foundations were larger than the natural foundation. 


\section{MATEC Web of Conferences}

To facilitate comparison of characteristic value of bearing capacity of composite foundation, we took the corresponding equal $\mathrm{s} / \mathrm{b}=0.008$ in the same conditions of the pile diameter, the pile length and area replacement ratio. The CSP composite foundation bearing capacity characteristic value was the highest, which was $220 \mathrm{kpa}$. GP composite foundation bearing capacity characteristic value was the minimum, which was $203 \mathrm{kpa}$.

\subsection{Composite foundation load test fitting curve}

Natural foundation, CFGP, CSP and GP composite foundation $\mathrm{p}$-s curve had obvious nonlinear relationship. The p-s curve used index form for nonlinear fitting, and the general form of the curve is as follows:

$$
s=s_{0}+A \exp (p / t)
$$

$s_{0}$ and $A_{\&} t$ were the fitting coefficients.

Table 3 and Figures 8-11 show natural foundation, CSP, and the fitting coefficient of CFGP composite foundation. The autocorrelation coefficient of the fitted curve was greater than 0.99 .

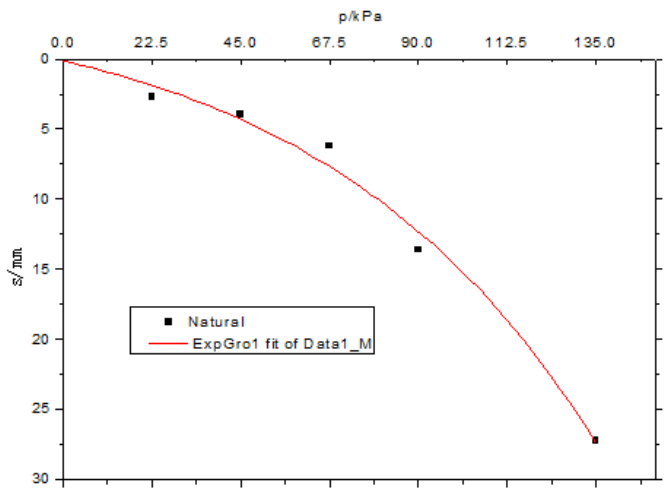

Figure 8 . The natural foundation fitting curve

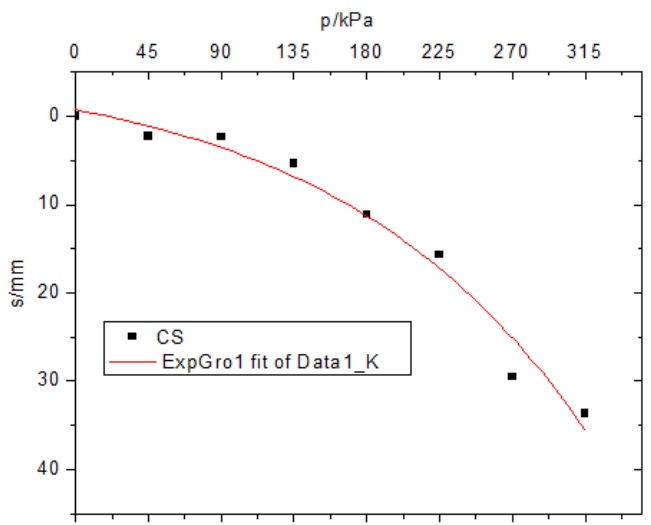

Figure 9. The CSP fitting curve

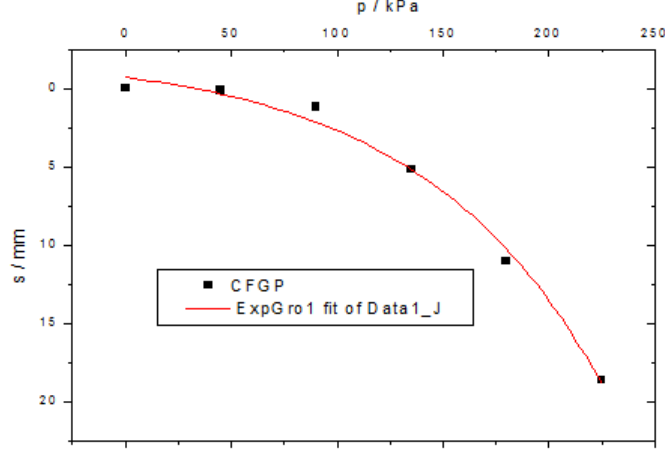

Figure 10. The CFG fitting curve

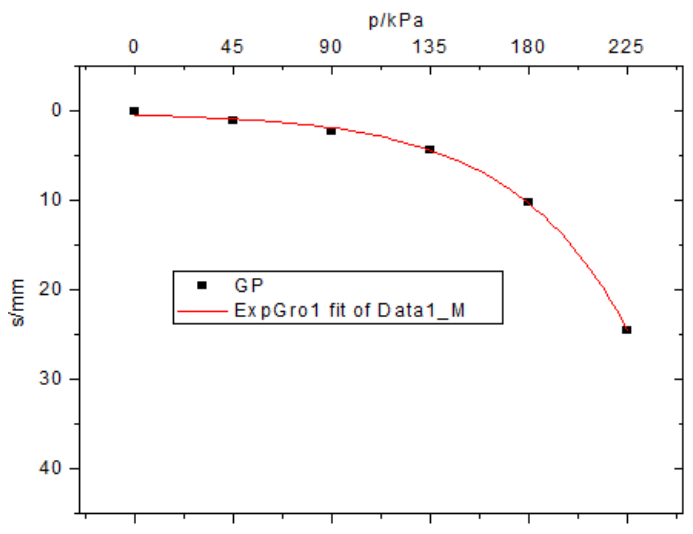

Figure 11. The GP fitting curve

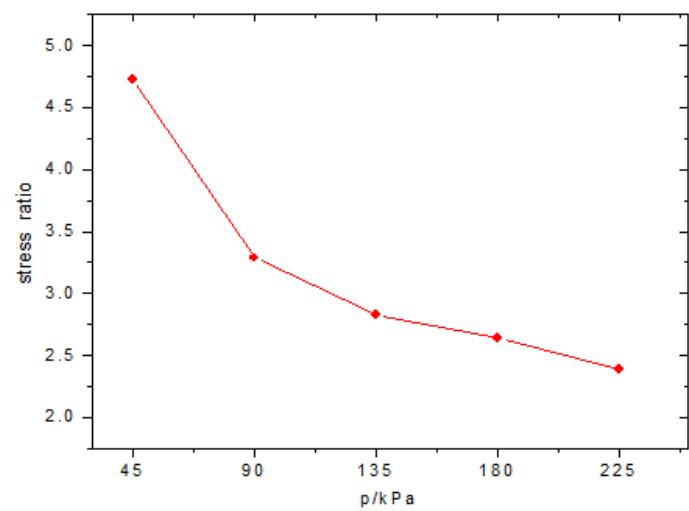

Figure 12. GP of pile-soil stress ratio

\subsection{Analysis of stress ratio of pile-soil}

According to field test data, the analysis of the stress on pile top and soil between piles, pile-soil stress ratio under different ground treatment methods of mathe- 
ICETA 2015

Table 3. Different composite foundation load test fitting curve function of various factor and bearing capacity

\begin{tabular}{l|l|l|l|l|l}
\hline \multirow{2}{*}{$\begin{array}{l}\text { Type of composite founda- } \\
\text { tion }\end{array}$} & \multicolumn{3}{|l|}{$\mathrm{y}=\mathrm{y}_{0}+\mathrm{Ae}^{(\mathrm{p} / t)}$} & $\begin{array}{l}\text { The correlation coeffi- } \\
\text { cient }\end{array}$ & $\begin{array}{l}\text { The bearing capacity } \\
/ \mathrm{kPa}\end{array}$ \\
\cline { 2 - 5 } & $\mathrm{A}$ & $\mathrm{y}_{0}$ & $\mathrm{t}$ & & 90 \\
\hline natural foundation & 4.72225 & -4.60977 & 70.57301 & 0.995123 & 220 \\
CSP & 1.29126 & -0.73233 & 85.89419 & 0.996138 & 212 \\
CFGP & 1.5446 & -2.24319 & 85.98827 & 0.996263 & 203 \\
\hline GP & 0.30712 & 0.09546 & 51.41749 & 0.99958 & 2038 \\
\hline
\end{tabular}

matical statistics was studied. The results were shown in Table 4. Pile-soil stress ratio of CFG pile was greater than the CSP composite foundations', and CSP's pile-soil stress ratio of composite foundation was greater than the GP composite foundations'. GP, CFG and CSP of pile-soil stress ratio were shown Figures 12-14.

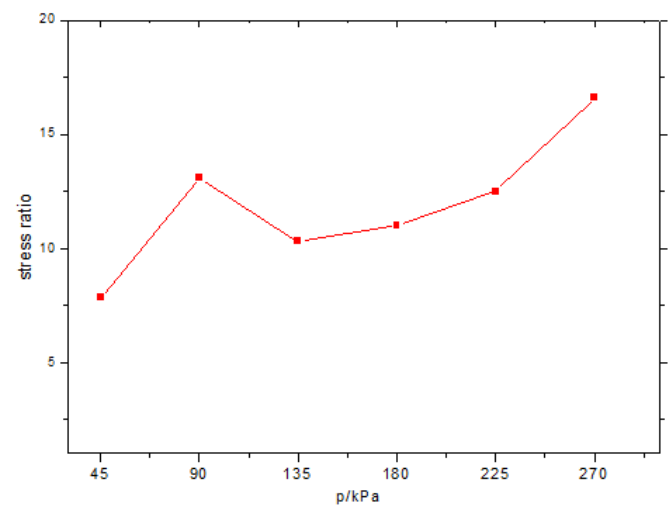

Figure 13. CFG of pile-soil stress ratio

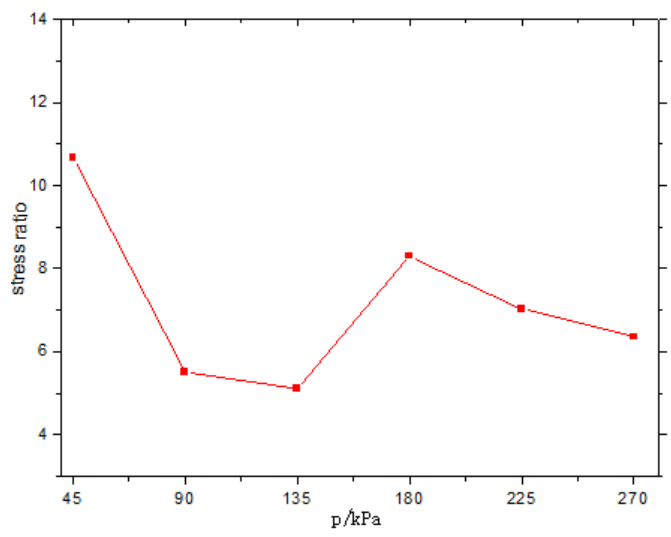

Figure 14. CSP of pile-soil stress ratio
4.4 Deformation modulus of composite foundation

According to the p-s curve of composite foundation and composite foundation deformation modulus, the formula is as follows:

$$
E_{0}=\frac{p b\left(1-\mu^{2}\right)}{s} \omega
$$

p: Curve fitting straight line segment of load intensity $(\mathrm{kPa})$;

$\mathrm{S}$ : The corresponding coefficient to $\mathrm{p}$ which is the sink of the load board (mm);

$\mathrm{b}$ : The width of the loading plate (mm);

$\mu$ : The poisson's ratio of soil;

$\omega$ : The settlement influence coefficient.

The rigid loading plate takes $\omega=0.88$ (square plate); $\omega=0.79$ (round).

The poisson's ratio of composite foundation by the area weighted average calculation, single pile and the poisson's ratio of composite foundation press type calculation are as follows:

$$
\mu_{s p}=m \mu_{p}+(1-m) \mu_{s}
$$

$\mu_{p s}$ : Poisson's ratio of composite foundation;

$\mu_{s}$ : Poisson's ratio of soil between piles;

$\mu_{p}$ : Pile material poisson's ratio;

$\mathrm{m}$ : The area of the pile soil replacement rate.

Two kinds of the poisson's ratio of pile type are combined with pile composite foundation press type calculation:

$\mu_{s p}=m_{1} \mu_{p 1}+m_{2} \mu_{p 2}+\left(1-m_{1}-m_{2}\right) \mu_{s}$

$\mu_{p 1}$ : The first pile material of poisson's ratio;

$\mu_{p 2}$ : The second kind of pile material poisson's ratio;

$\mathrm{m}_{1}$ : The first kind of pile type of replacement rate;

$\mathrm{m}_{2}$ : The second kind of pile type of replacement rate.

The poisson's ratio of CFGP takes 0.23 ; Poisson's ratio of CSP takes 0.26 ; the soil between piles of poisson's ratio take 0.3 . According to the p-s curve of the composite foundation, the deformation modulus was shown in Table 5. The CSP, CFGP, and GP deformation modulus of composite foundation were 31.51 Mpa, 60.49 Mpa and 71.57 Mpa. 
MATEC Web of Conferences

Table 4. Pile soil stress ratio of composite foundation

\begin{tabular}{l|l|l|l|l|l}
\hline Type of composite foundation & $\begin{array}{l}\text { The maxi- } \\
\text { mum }\end{array}$ & $\begin{array}{l}\text { The minimum } \\
\text { value }\end{array}$ & The average & $\begin{array}{l}\text { The standard } \\
\text { deviation }\end{array}$ & $\begin{array}{l}\text { Coefficient } \\
\text { variation }\end{array}$ \\
\hline CSP & 10.67 & 4.93 & 6.51 & 1.55 & 0.24 \\
\hline CFGP & 16.59 & 7.83 & 11.88 & 2.7 & 0.23 \\
\hline GP & 4.72 & 2.39 & 3.18 & 0.83 & 0.26 \\
\hline
\end{tabular}

Table 5. Composite foundation deformation modulus

\begin{tabular}{l|l|l|l}
\hline Type of composite foundation & CSP & CFGP & GP \\
\hline Deformation modulus $/ \mathrm{MPa}$ & 31.51 & 60.49 & 71.57 \\
\hline
\end{tabular}

\section{CONCLUSIONS}

Through the natural foundation, rammed soil-cement piles, CFG pile and gravel pile composite foundation for the large scale static load test, the following conclusions are drawn:

1) By p-s curve, when the load was $225 \mathrm{kpa}$, CSP composite foundation settlement was minimum. When the load of GP composite foundation was $135 \mathrm{kpa}$, settlement of GP was less than and CSP and CFGP composite foundation of composite foundation settlement. The p-s curves of Natural foundation, rammed soil-cement pile and CFG pile foundation, were obviously nonlinear characteristics.

2) Through the statistical analysis of the stress ratio of pile-soil load, pile soil stress ratio of CFG pile was greater than rammed soil-cement pile composite foundation, whereas the CSP pile-soil stress ratio of composite foundation was greater than the GP composite foundation.

3) Through the reflex composite foundation, the deformation modulus is $\mathrm{ECSP}<\mathrm{ECFG}<\mathrm{EGP}$.

\section{ACKNOWLEDGEMENT}

This work was supported by Department of Housing \& Urban-rural Development in Hebei (2008-113).

\section{REFERENCES}

[1] Peng Bao, Xiliang Jiang. \& Guilin Sheng. 2007. Static and dynamic anslysis of bearing capacity of composite foundation of concrete core mixing piles, Rock and Soil Mechanics. 28(1): 63-82.

[2] Weiyu Wang, Tuo Zhao. \& Jihui Ding. 2010. The dynamic characteristics of $\mathrm{CFG}$ pile composite foundation and the analysis of time history response factors. Journal of geotechnical engineering. S2(215): 115-118

[3] Tuo Zhao, Changmin Yang. \& Weiyu Wang. 2010. The experimental study of dynamic characteristics of $\mathrm{CFG}$ pile composite foundation under blasting load. Highway traffic technology (technology). 7(67): 121-122.

[4] Weiyu Wang, Tuo Zhao. \& Yanjie Meng. 2012. Blasting vibration dynamic characteristics of the CFG pile composite foundation under the action of numerical analysis. Engineering mechanics. 29(s1): 150-155.

[5] Jihui Ding, Junhui Feng. \& Man Yuan. 2011. Approxmate Solution of Seimic Bearing Capcity of Composite Foundation under Earthquake Action, IEEE International Workshop on A hitecture, Civil \& Environmental Engineering.

[6] Zhou Dequan, Zhang Keneng. \& Liu Hongli. 2004. Application and calculation analysis of combined pile composite foundation. Rock and Soil Mechanics, 25 (9): $1432-1436$.

[7] Zhihua Yang. \& Qing Yang. 2008. Vbration performance time history analysis of soil-cement mixing pile composite foundation. Rock and Soil Mechanics. 29(3): 805-810.

[8] Ziguo Xu. \& Erxiang Song. 2004. Finite element analysis on seismic behavior of rigid pile composite foundation. Rock and soil mechanics. 25(2): 179-184.

[9] Technical code for ground treatment of buildings, China Building Industry Press, 2012. 